\title{
A study on association of preoperative anaemia and obesity with causes and postoperative outcome in women undergoing hysterectomy for abnormal uterine bleeding
}

\author{
S. Manju Parkavi, M. Jayasree*, R. Sasikala
}

Department of Obstetrics and Gynecology, Sri Manakula Vinayagar Medical College and Hospital, Pondicherry, India

Received: 08 March 2018

Accepted: 03 April 2018

*Correspondence:

Dr. M. Jayasree,

E-mail: drmjayasree1@yahoo.co.in

Copyright: ( $)$ the author(s), publisher and licensee Medip Academy. This is an open-access article distributed under the terms of the Creative Commons Attribution Non-Commercial License, which permits unrestricted non-commercial use, distribution, and reproduction in any medium, provided the original work is properly cited.

\begin{abstract}
Background: Abnormal uterine bleeding is most commonly encountered in 10-20\% of women in reproductive age. The objectives of the study are to assess the proportion and association with causes and postoperative outcome of preoperative anaemia and obesity in women with abnormal uterine bleeding who underwent hysterectomy.

Methods: This was a retrospective observational record-based study conducted in the Dept. of Obstetrics and Gynaecology of Sri Manakula Vinayagar Medical College and Hospital(SMVMCH), Pondicherry. The study population consisted of 169 patients who were admitted for abnormal uterine bleeding and underwent hysterectomy from January 2016 to December 2016 for a period of one year.

Results: The mean age was 43years. The mean value of haemoglobin on admission was $9.89 \mathrm{~g} / \mathrm{dl}$. The distribution frequencies of patients by WHO BMI classification as underweight, normal, overweight and obesity are 8, 59, 78 and 24 respectively. The distribution frequencies of patients by WHO anaemia classification as no anaemia, mild, moderate are 34, 37 and 98 respectively. Seventy-six patients had blood transfusion. Six patients had urinary tract infection and all of them were anaemic and obese. Two patients had developed respiratory tract infection and none of the patients had developed deep vein thrombosis.

Conclusions: Preoperative anaemia was more common in patients with fibroid and associated with increased morbidity in immediate postoperative period. There is more prevalence of SSI among overweight and obese women.
\end{abstract}

Keywords: Abnormal uterine bleeding, Hysterectomy, Overweight, Obesity, Preoperative anaemia

\section{INTRODUCTION}

Abnormal uterine bleeding is most commonly encountered in $10-20 \%$ of women in reproductive age. Even though various medical managements and noninvasive methods are available for management of abnormal uterine bleeding, hysterectomy is the permanent treatment option. Most of the modern treatments available to women in high resource settings or developed countries are not an option for women in low resource areas. Tamilnadu government insurance scheme also covers only laparoscopic assisted hysterectomy while medical management with LNG-IUS or endometrial ablation procedures are not covered. The aim of preoperative evaluation is to enhance surgical outcome. Pre-operative anaemia is found to be an independent risk factor of morbidity and mortality. Heavy menstrual bleeding in reproductive age group is most common cause for iron deficiency anaemia which leads to many complications in a women life. In a retrospective study done in Harbor-UCLA Medical Center in Torrance, California during the six years 2008-2013out of 271 
premenopausal women who were treated for severe anaemia, 55\% of them had heavy menstrual bleeding. Of which $7.8 \%$ considered their menses to be normal; while $7 \%$ learned of their problem only as result of routine screening for other reasons. ${ }^{1}$ There is controversy regarding association between obesity and postoperative morbidity and mortality. 2,3

The objectives of the study are to assess the proportion of preoperative anaemia and obesity in women with abnormal uterine bleeding, to assess the association between preoperative anaemia and causes of abnormal uterine bleeding and to evaluate the effect of preoperative anaemia and obesity on immediate postoperative outcome like duration of hospital stay, urinary tract infection, respiratory tract infection, deep venous thrombosis, and surgical site infection.

\section{METHODS}

This was a retrospective observational record-based study conducted in the Dept. of Obstetrics and Gynaecology of Sri Manakula Vinayagar Medical College and Hospital(SMVMCH), Pondicherry. The study population consisted of 169 patients who were admitted for abnormal uterine bleeding and underwent hysterectomy from January 2016 to December 2016 for a period of one year. The inclusion criterion was women in reproductive age group (15-49) years that underwent hysterectomy for abnormal uterine bleeding. The exclusion criterion was women in reproductive age group that underwent hysterectomy for other indications like malignancy, prolapse. The data was collected from the file records which included patient age, parity, body mass index(BMI), complaints, indication for surgery, comorbidities like hypertension, hypothyroidism and diabetes, type of hysterectomy, duration of surgery, amount of blood loss during surgery, duration of stay in hospital, admission, preoperative and postoperative hemoglobin, blood transfusion, fever, urinary tract infection, surgical site infection, type of anaesthesia, and histopathalogical report.

According to WHO haemoglobin $<12 \mathrm{~g} / \mathrm{dl}$ is considered anaemia in reproductive age group women. Mild, moderate and severe anaemia is classified with hemoglobin between $11-11.9 \mathrm{~g} / \mathrm{dl}, 8-10.9 \mathrm{~g} / \mathrm{dl}$ and $<8 \mathrm{~g} / \mathrm{dl}$ respectively. ${ }^{4}$ According to $\mathrm{WHO}$ nutritional status is classified into underweight, normal, pre-obesity and obesity when BMI <18.5, 18.5-24.9, 25-29.9, >30 respectively. ${ }^{5}$

\section{Statistical analysis}

Data was entered into Microsoft excel data sheet and was analyzed using SPSS 22 version software. Categorical data was represented in the form of frequencies and percentage chi square test used as test of significance for qualitative data.

\section{RESULTS}

In the present study $89 \%$ of women were $<50$ years and $11 \%$ were $>50$ years. The mean age was 43 years with SD 6.849. The highest number of AUB was found in para $2(44.4 \%)$ followed by para $3(34.3 \%)$. The mean value of haemoglobin on admission was $9.89 \mathrm{~g} / \mathrm{dl}$ with SD 2.187. The mean value of haemoglobin preoperatively was 10.846 with SD 1.2405. The mean value of haemoglobin postoperatively was 10.556 with SD 1.5171. The mean value of amount of blood loss during surgery was $119.94 \mathrm{ml}$ with SD 95.964.

Table 1: Distribution of Patients by BMI

\begin{tabular}{|lll|}
\hline BMI & Frequency & Percentage \\
\hline Underweight & 8 & $4.7 \%$ \\
\hline Normal & 59 & $36.1 \%$ \\
\hline Overweight & 78 & $46.7 \%$ \\
\hline Obese & 24 & $12.4 \%$ \\
\hline Total & 169 & $100 \%$ \\
\hline
\end{tabular}

The frequency of patients who underwent abdominal, vaginal and laparoscopic assisted vaginal hysterectomy was 146,13 and 10 respectively. Eleven patients had coexisting hypertension, twelve had Diabetes and twelve had hypothyroidism.

Table 2: Distribution by type of anemia with respect to World Health Organization

\begin{tabular}{|llll|}
$\begin{array}{l}\text { Type of } \\
\text { Anemia }\end{array}$ & On & On Pre- & On Post \\
Opersion & Operation & Operation \\
\hline $\begin{array}{l}\text { No } \\
\text { Anemia }\end{array}$ & $26(15.3 \%)$ & $34(20.1 \%)$ & $19(11.2 \%)$ \\
$\begin{array}{l}\text { Mild } \\
\text { Anemia }\end{array}$ & $28(16.5 \%)$ & $37(21.8 \%)$ & $54(31.9 \%)$ \\
\hline $\begin{array}{l}\text { Moderate } \\
\text { Anemia }\end{array}$ & $87(51.4 \%)$ & $98(57.9 \%)$ & $96(56.8 \%)$ \\
\hline $\begin{array}{l}\text { Severe } \\
\text { Anemia }\end{array}$ & $27(15.9 \%)$ & 0 & 0 \\
\hline
\end{tabular}

Table 3: Preoperative Anaemia and SSI

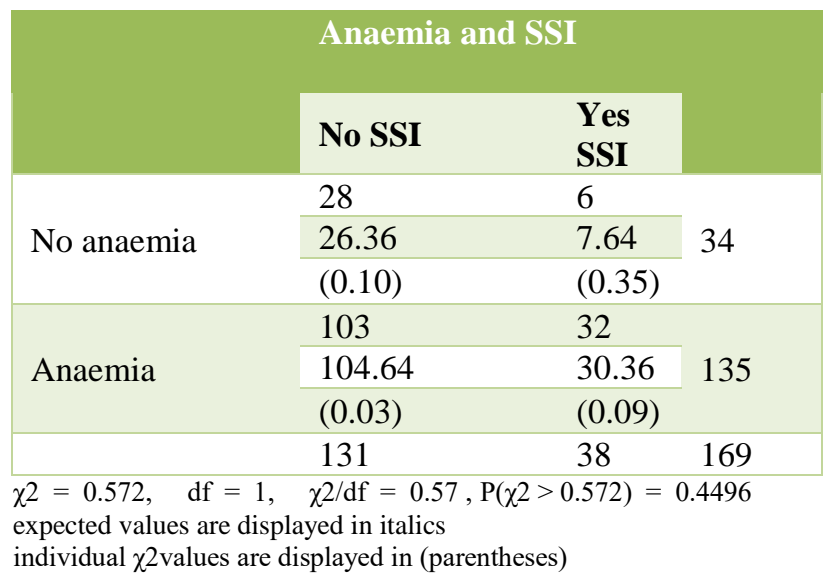


The mean value of duration of stay in days was 12.775 with SD 3.8401. Patients get admitted 2 days prior to surgery and get discharged on postoperative day 8 .

The frequency of patients with duration of stay for more than 13 days was 55 . Out of which were 50 were anaemic and 34 were overweight and obese. In 32 patients with extended stay both was co-existng. The duration of surgery was prolonged in 14 patients. All these patients were both anaemic and obese. One hundred and fifty patients underwent endometrial biopsy before hysterectomy. the frequency of patients with endometrial pattern types of simple hyperplasia without atypia, complex hyperplasia, proliferative endometrium, shedding endometrium, secretory endometrium were 46,14, 37, 34,19 respectively. According to PALMCOEIN classification of AUB causes, women diagnosed with polyp, fibroid, adenomyosis, malignancy and hyperplasia group were $11,46,22$, and 60 respectively. Hyperplastic endometrium was found along with fibroid uterus in 14 women. Seventy-six patients had blood transfusion. Six patients had urinary tract infection and all of them were anaemic and obese. Two patients had developed respiratory tract infection and none of the patients had developed deep vein thrombosis.

\section{DISCUSSION}

In the present study nearly $83 \%$ of women had preoperative anaemia and $60 \%$ were overweight and obese. Twenty three percent of anaemic patients and twenty two percent of overweight and obese patients had SSI. The duration of stay was prolonged in $65 \%$ and $66 \%$ of patients with overweight and obesity and anaemia respectively. According to Global Nutrition Report 2017 in India 51 per cent of the women of reproductive age suffer from anaemia and more than 22 per cent of adult women are overweight $(\mathrm{BMI}>25)$ and $5 \%$ were obese $(\mathrm{BMI}>30){ }^{6}$

In 18 large observational studies encompassing over 650,000 surgical patients, the mean prevalence of preoperative anaemia was around $45-50 \%$ among gynaecological patients.5 In a study done among women presenting to an emergency facility with AUB, 35\% were found to be with anaemia of which $14 \%$ were moderately to severe anemic. ${ }^{7}$ In a nationwide sample done in USA $25 \%$ of women hospitalized for HMB had anaemia. ${ }^{8}$ In the present study the proportion of preoperative anaemia was $83 \%$ and of which $66 \%$ of women were moderately to severe anaemic.

In the present study the histological examination revealed more cases of PALM component of AUB. In the present study $58 \%$ women with AUB were diagnosed with fibroid and13\% with adenomyosis when compared to another study where AUB-M (hyperplasia and malignancy) contributed to PALM component. In a study done in University of Ghana, $77.9 \%$ of women with uterine fibroids had anaemia. ${ }^{9}$ In another study done on clinical presentation and prevalence of uterine fibroids in rural South India, $68 \%$ of women with fibroids had anaemia. ${ }^{10}$ Leiomyoma were identified as the cause of bleeding in $47.9 \%$ of subjects, in study done in Mayo clinic. In women diagnosed with submucosal fibroid by hysteroscopy $38 \%$ had anaemia and $28 \%$ of women diagnosed as fibroid by ultrasound irrespective of location had anaemia. ${ }^{11}$ In the present study $84 \%$ of women diagnosed as fibroid by histopathology had anaemia. We have not classified fibroid according to location. In another study which correlated anaemia and pain with location of uterine fibroid, no difference in anaemia was noted in the submucosal group as compared to the non-submucosal group (43.2\% vs. $31.5 \%$ [OR 1.5]; $95 \%$ CI $0.9,2.6) .^{12}$

In a study where comorbidity of gynaecological and nongynaecological diseases associated with adenomyosis and fibroid the mean OR of anaemia unspecified, iron deficiency anaemia, other iron deficiency anaemia is 1.3 , 1.4, 1.6 respectively in women diagnosed with adenomyosis. ${ }^{13}$ Anaemia was easily anticipated as a comorbid disease of adenomyosis because menorrhagia is one of the primary symptoms. ${ }^{14}$ In the present study out of 22 women diagnosed with adenomyosis, $90 \%$ had associated anaemia.

All patients with severe anaemia $<8 \mathrm{~g} / \mathrm{dl}$ had preoperative blood transfusion. Almost half of the patients $52 \%$ with moderate anaemia had perioperative blood transfusion and $21 \%$ of patients with mild anaemia had postoperative transfusion. In a data analysis of women undergoing major gynaecological surgery in Australia, the prevalence of preoperative anaemia is $18.1 \%$ and it is associated with increased risk of receiving blood transfusion. Preoperative anaemia is common in patients undergoing major gynaecological surgery and is associated with a fivefold increased risk of transfusion. ${ }^{15}$ In a retrospective review of hysterectomies the preoperative factors which were associated with transfusion were hematocrit $<30$, indication for surgery is fibroid/ menorrhagia (OR 3.2; confidence interval $[\mathrm{CI}]$ : 1.4-7.4), women undergoing abdominal hysterectomy (OR 3.4; C.I. 2.0-5.7) than vaginal/total laparoscopic hysterectomy. There were no differences in baseline age, race, body mass index (BMI), or tobacco use between transfused and non-transfused patients. ${ }^{16}$ In a prospective cohort study done to determine the relationship between preoperative anaemia and perioperative blood transfusion with incidence of surgical site infection, there was a significant association, but the association reduced when the confounder is duration of surgery. ${ }^{17}$

The percentage of patients with complex hyperplasia in the present study was $8 \%$. In a retrospective cohort study to evaluate the effect of BMI on endometrial hyperplasia and cancer done in Auckland where half of the study cohort is obese, complex hyperplasia was diagnosed in $4.9 \%$ and the risk factors associated were obesity, anaemia and nulliparity. ${ }^{18}$ Overweight and obesity were 
also considered as risk factors for adenomyosis. ${ }^{19}$ But In the present study there was no statistical significant increased risk of adenomyosis $(\chi 2=0.001, \mathrm{df}=1, \chi 2 / \mathrm{df}$ $\left.=0.00, \mathrm{P}\left(\chi^{2}>0.001\right)=1.1064\right)$ and complex hyperplasia $\left(\chi 2=0.009, \mathrm{df}=1, \chi^{2} / \mathrm{df}=0.01, \mathrm{P}\left(\chi^{2}>\right.\right.$ $0.009)=0.9367$ )in overweight and obese women.

In the present study $22 \%$ of patients had surgical site infection. In patients with SSI, $87 \%$ had preoperative anaemia. The frequency of SSI among patients with severe anaemia, moderate anaemia and mild anaemia was $30 \%, 23 \%$ and $18 \%$ respectively. If we take the disease as SSI and the exposed as who are anaemic then the population attributable risk is 0.06214 , the population exposure is $81.6 \%$, and the population attributable risk percent is $28.4 \%$. In a study done among non-cardiac surgery patients where preoperative anaemia and postoperative outcome were compared there was no significant difference in SSI, fever and in-hospital mortality between anaemic and non anaemic patients. ${ }^{20}$ In a cohort study using data from the ACS NSQIP database, the odds ratio of wound infection in patients with preoperative anaemia is $1.66(1.20-2.21) .{ }^{21}$

In the present study also, the duration of surgery was prolonged and was more than 2 hours in all obese patients. In another study from India, the duration of vaginal hysterectomy was slightly longer in obese women, but the time was longest for women with abdominal hysterectomy. ${ }^{22}$ In a cohort study done among women undergoing hysterectomy for benign conditions in Denmark, $31.9 \%$ were classified as overweight and $17.5 \%$ as obese. There is significant association between high BMI and operation time. ${ }^{23}$

In the present study $86 \%$ of overweight and obese and $79 \%$ of women with underweight and normal weight had anaemia. In a study where nationally representative data from Mexico (1998 National Nutrition Survey), Peru and Egypt (2000 Demographic and Health Surveys) were analyzed, overweight women from Mexico were equally as likely to suffer from anaemia as non- overweight women. But in Egypt and Peru, though overweight women still suffer from anaemia at higher rate but have lower odds of anaemia than non- overweight women. ${ }^{24}$ In a study done in AndraPradesh, India, women with overweight/obesity or central obesity were less likely to be anaemic as compared to normal weight women. ${ }^{25}$ Based on a study using Bangladesh Demographic and health survey 2011 data ,being underweight and normal weight is strongly associated with anaemia in adult women. ${ }^{26}$ In premenopausal Thailand women irrespective of iron status higher BMI was associated with poor iron absorption. ${ }^{27}$ This may be due to hepcidin-mediated reduced iron absorption and/or increased iron sequestration. ${ }^{28}$

Twenty-three patients had both obesity and anaemia and associated with SSI. In another nationwide Sweden study, BMI $>28 \mathrm{~kg} / \mathrm{m}^{2}$ was a risk factor for infection after elective $\mathrm{AH}^{29}$ In a retrospectively collected data from 2006-2010 National Surgical Quality Improvement Program the odds ratio of wound infections after abdominal hysterectomy in overweight and obese women is 1.7 and 3.0 respectively. There is a positive association between increasing BMI and increasing odd of SSI. ${ }^{30}$

\section{CONCLUSION}

Preoperative anaemia was more common in patients with fibroid and associated with increased morbidity in immediate postoperative period. There is more prevalence of SSI among overweight and obese women. Further studies are needed to assess if the management of preoperative anaemia has any impact on patient outcomes.

\section{Funding: No funding sources Conflict of interest: None declared \\ Ethical approval: The study was approved by the Institutional Ethics Committee}

\section{REFERENCES}

1. Nelson AL, Ritchie JJ. Severe anemia from heavy menstrual bleeding requires heightened attention Am J Obstet Gynecol. 2015;213:97.

2. Young H, Bliss R, Carey JC, Price CS. Beyond core measures: Identifying modifiable risk factors for prevention of surgical site infection after elective total abdominal hysterectomy. Surg Infect (Larchmt). 2011;12:491-6.

3. Mahdi H, Jernigan AM, Aljebori Q, Lockhart D, Moslemi-Kebria M. The impact of obesity on the 30day morbidity and mortality after surgery for endometrial cancer. J Minim Invasive Gynecol. 2015;22:94-102.

4. WHO. Haemoglobin concentrations for the diagnosis of anaemia and assessment of severity. 2011. Availabile www.who.int/vmnis/indicators/haemoglobin.pdf

5. World Health Organization. Body mass index - BMI. Available at http://www.euro.who.int/en/healthtopics/disease-prevention/nutrition/a-healthylifestyle/body-mass-index-bmi

6. Global nutrition report. Nourishing the SDGs. Available at www.globalnutritionreport.org/thereport/

7. Muñoz M, Gómez-Ramírez S, Campos A, Ruiz J, Liumbruno GM. Pre-operative anaemia: prevalence, consequences and approaches to management. Blood Transfusion. 2015;13:370.

8. Matteson KA, Raker CA, Pinto SB, Scott DM, Frishman GN. Women presenting to an emergency facility with abnormal uterine bleeding: patient characteristics and prevalence of anemia. J Reprod Med. 2012;57:17-25.

9. Morrison J, Patel ST, Watson W, Zaidi QR, Mangione A, Goss TF. Assessment of the prevalence and impact of anemia on women hospitalized for 
gynecologic conditions associated with heavy uterine bleeding. J Reprod Med. 2008;53:323-30.

10. Munusamy MM, Sheelaa WG, Lakshmi VP. Clinical presentation and prevalence of uterine fibroids: a 3year study in 3-decade rural South Indian women. Int J Reprod Contracept Obstet Gynecol. 2017;6:5596601.

11. Puri K, Famuyide AO, Erwin PJ, Stewart EA, Laughlin-Tommaso SK. Submucosal fibroids and the relation to heavy menstrual bleeding and anemia. Am J Obstet Gynecol. 2014;210:38.e1-7.

12. Bachmann GA, Bahouth LA, Amalraj P, Mhamunkar $\mathrm{V}$, Hoes $\mathrm{K}$, Ananth CV. Uterine fibroids: Correlations of anemia and pain to fibroid location and uterine weight. J Reprod Med. 2011;56:463-6.

13. Choi EJ, Cho SB, Lee SR, Lim YM, Jeong K, Moon HS, Chung H. Comorbidity of gynecological and non-gynecological diseases with adenomyosis and endometriosis. Obstet Gynecol Sci. 2017;60:57986.

14. Shrestha A, Sedai LB. Understanding clinical features of adenomyosis: a case control study. Nepal Med Coll J. 2012;14:176-9.

15. Browning RM, Trentino K, Nathan EA, Hashemi N. Preoperative anaemia is common in patients undergoing major gynaecological surgery and is associated with a fivefold increased risk of transfusion. Aust NZJ Obstet Gynaecol. 2012;52:455-9.

16. Kane S, Collins S, Sproat LA, Mangel J. Predictors of transfusion requirement among patients who undergo hysterectomy for benign disease. J Gynecol Surg. 2012;28:113-5.

17. Weber WP, Zwahlen M, Reck S, Misteli H, Rosenthal R, Buser AS, et al. The association of preoperative anemia and perioperative allogeneic blood transfusion with the risk of surgical site infection. Transfusion. 2009;49:1964-70.

18. Wise MR, Gill P, Lensen S, Thompson JM, Farquhar CM. Body mass index trumps age in decision for endometrial biopsy: cohort study of symptomatic premenopausal women. Am J Obstet Gynecol. 2016;215:598.e1-8.

19. Trabert B, Weiss NS, Rudra CB, Scholes D, Holt VL. A case-control investigation of adenomyosis: impact of control group selection on risk factor strength. Women's health issues: Jacobs Inst of Women's Health. 2011;21:160-4.

20. Amponsah G, Charwudzi A. Preoperative anaemia and associated postoperative outcomes in Noncardiac surgery patients in central region of Ghana. Anesthesiol Res Pract. 2017;2017.

21. Richards T, Musallam KM, Nassif J, Ghazeeri G, Seoud M, Gurusamy KS et al. Impact of preoperative anaemia and blood transfusion on postoperative outcomes in gynaecological surgery. Plos One. 2015;10:e130861.

22. Sheth SS. Vaginal hysterectomy as primary route for morbidly obese women. Acta Scand Gynecol 2010;89:971-4.

23. Anipindi G. Postoperative morbidity in women following major gynaecological surgery. J Evid Based Med Health. 2017;4:5571-6.

24. Eckhardt CL, Torheim LE, Monterrubio E, Barquera S, Ruel MT. The overlap of overweight and anaemia among women in three countries undergoing the nutrition transition. Eur J Clin Nutr. 2008;62:238-46.

25. Hemamalini J. Anemia in relation to body mass index and waist circumference among Andhra Pradesh women. J Obes Weight Loss Ther. 2013;3:173.

26. Ghose B, Yaya S, Tang S. Anemia status in relation to body mass index among women of childbearing age in Bangladesh. Asia Pac J Public Health. 2016;28:611-9.

27. Cepeda-Lopez AC, Aeberli I, Zimmermann MB. Does obesity increase the risk for iron deficiency? A review of the literature and the potential mechanisms. Int J Vitam Nutr Res. 2010;80:263-70.

28. Aigner E, Feldman A, Datz C. Obesity as an emerging risk factor for iron deficiency. Nutr. 2014;6:3587-600.

29. Lofgren M, Poromaa IS, Stjerndahl JH, Renstrom B. Postoperative infections and prophylaxis for hysterectomy in Sweden: a study by the Swedish National Register for Gynecologic surgery. Acta Obstet Gynecol Scand. 2004;83:1202-7.

30. Khavanin N, Lovecchio FC, Hanwright PJ, Brill E, Milad M, Bilimoria KY, et al. The influence of BMI on perioperative morbidity following abdominal hysterectomy. Am J Obstet Gynecol. 2013;208:449.e1-6.

Cite this article as: Parkavi P, Jayasree M, Sasikala. A study on association of preoperative anaemia and obesity with causes and postoperative outcome in women undergoing hysterectomy for abnormal uterine bleeding. Int J Reprod Contracept Obstet Gynecol 2018;7:2002-6. 